\title{
Corrigendum: The Effects of Money on Fake Rating Behavior in E-Commerce: Electrophysiological Time Course Evidence From Consumers
}

OPEN ACCESS

Approved by:

Frontiers in Neuroscience

Editorial Office,

Frontiers Media SA, Switzerland

${ }^{*}$ Correspondence:

Huijian Fu

huijian_fu@gdut.edu.cn

Specialty section:

This article was submitted to

Neural Technology,

a section of the journal

Frontiers in Neuroscience

Received: 12 February 2019

Accepted: 18 February 2019

Published: 11 March 2019

Citation:

Wang C, Li Y, Luo X, Ma Q, Fu W and

Fu H (2019) Corrigendum: The Effects

of Money on Fake Rating Behavior in

E-Commerce: Electrophysiological

Time Course Evidence From

Consumers. Front. Neurosci. 13:192.

doi: 10.3389/fnins.2019.00192
Cuicui Wang ${ }^{1,2,3}$, Yun Li ${ }^{1,2}$, Xuan Luo ${ }^{1,2}$, Qingguo Ma ${ }^{3,4,5}$, Weizhong Fu ${ }^{1,2}$ and Huijian Fu ${ }^{\text {* }}$

${ }^{1}$ School of Management, Hefei University of Technology, Hefei, China, ${ }^{2}$ Key Laboratory of Process Optimization and Intelligent Decision-Making, Hefei University of Technology, Ministry of Education, Hefei, China, ${ }^{3}$ Academy of Neuroeconomics and Neuromanagement, Ningbo University, Ningbo, China, ${ }^{4}$ Business School, Ningbo University, Ningbo, China, ${ }^{5}$ Institute of Neural Management Sciences, Zhejiang University of Technology, Hangzhou, China, ${ }^{6}$ School of Management, Guangdong University of Technology, Guangzhou, China

Keywords: fake rating behavior, money, N2, LPP, neuromarketing

\section{A Corrigendum on}

The Effects of Money on Fake Rating Behavior in E-Commerce: Electrophysiological Time Course Evidence From Consumers

by Wang, C., Li, Y., Luo, X., Ma, Q., Fu, W., and Fu, H. (2018). Front. Neurosci. 12:156. doi: 10.3389/fnins.2018.00156

There was an error in the Acknowledgments. The correct funding number for the "National Project" funder is "AWS14J011."

The authors apologize for this error and state that this does not change the scientific conclusions of the article in any way. The original article has been updated.

Copyright $\odot 2019$ Wang, Li, Luo, Ma, Fu and Fu. This is an open-access article distributed under the terms of the Creative Commons Attribution License (CC BY). The use, distribution or reproduction in other forums is permitted, provided the original author(s) and the copyright owner(s) are credited and that the original publication in this journal is cited, in accordance with accepted academic practice. No use, distribution or reproduction is permitted which does not comply with these terms. 